\title{
Deformation Calculation of HDPE Pipeline under Upper Load of Landfill Site
}

\author{
Zhou Taohong $^{1}$, Li Wei $^{2,3, a}$, He Yongxiang $^{1}$,Cai Hualong ${ }^{1}$, Frederick Nai \\ Charkley ${ }^{2,3}$
}

${ }^{1}$ Construction Management Services Center, Pingshan New District, Shenzhen 518000, China;

${ }^{2}$ Key Laboratory of Ministry of Education for Geomechanics and Embankment Engineering, Hohai University, Nanjing, 210098, China

${ }^{3}$ Geotechnical Research Institute, Hohai University, Nanjing, 210098, China

aemail: hhuliwei@sina.com

Keywords: Landfill Site; Pipeline; HDPE; Deformation; Upper Load

\begin{abstract}
The heap of new waste in landfills impose a large additional load on leachate pipelines constructed under existing landfill sites. There is urgent need to address safety problems caused by the new effect that is produced on these pipelines. Based on a modified Spangler model, the deformations of HDPE pipelines of different diameters and different wall thicknesses under garbage load were calculated and compared with design requirements. The calculation results show that the upper load has remarkable effect on the deformation of pipeline ring cross sections, the deflection of pipelines and loop tension stress of pipe walls. This was due to the differences of diameter and wall thickness of different HDPE pipelines which responded differently to the upper load.
\end{abstract}

\section{Introduction}

With rapid expansion of cities to cope with urbanization, the amount of municipal solid waste that is being generated increases day by day. In china, majority of the municipal solid waste produced are disposed by landfill [1]. However, most of the large number of landfill sites in the country were constructed many years ago and now their design capacity cannot meet the rapid growth of newly generated waste. This has heightened the need for expansion of landfill sites. The heap of new waste in landfills will impose a large additional load on the leachate pipelines of existing landfill sites, and new serious effects will be produced on the pipelines [2]. Therefore, it is very important to evaluate the safety of the pipelines under old landfill sites after the expansion of the landfill site.

Each part of the leachate collection system must have sufficient strength and rigidity to support the overlying load. Under the load of the upper garbage, the most easily damaged part of the leachate collection system is the collection and discharge pipelines. Too large deformations may cause bending failure to the pipeline such that the pipelines cannot function normally, which will subsequently affect the normal operation of the landfill site.

Leachate drainage systems are mainly composed of HDPE pipelines [3], these pipelines are mainly connected by flange connections and welding. The pipelines are arranged in an impervious layer, under the load of old landfill stress. This study examines the deformations caused in the HDPE pipelines and the effect of these deformations on the pipelines to verify whether the pipelines meet the standard requirements [4].

In this paper a new method of verifying the bearing capacity of HDPE pipelines which are used in landfill site is introduced based on the Spangler model engineering program.

\section{Determination of load and pipeline parameters of landfill site}

When the amount of new filled garbage reaches the design inventory, the pressure on the pipelines becomes greatest. Figure 1 shows the topographic map of a typical section on $\mathrm{Ya} \mathrm{Hu}$ 
Landfill site. From the topographic map, the maximum height of the landfill on the pipelines is $\mathrm{H}=58 \mathrm{~m}$, and the highest point is point A.The bulk density of the garbage is $\gamma=8 \mathrm{kN} / \mathrm{m}^{3}$. The pipelines were buried too deep without considerations for the influence of live load.

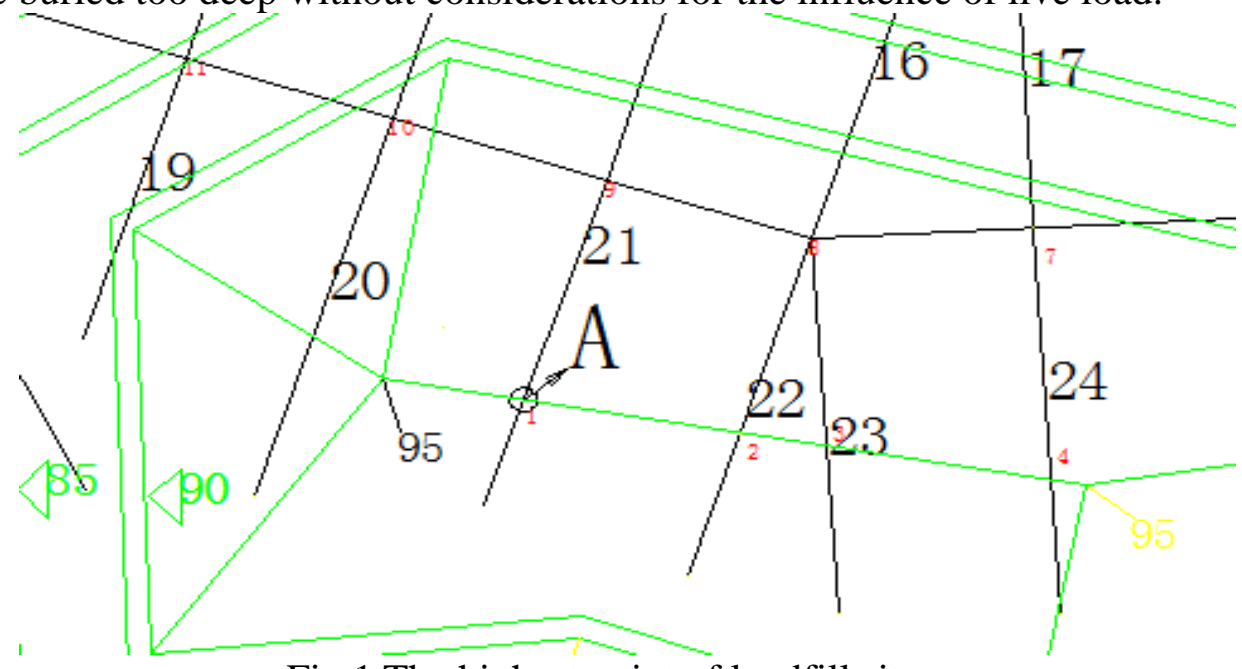

Fig. 1 The highest point of landfill site

So the maximum upper load is : $W=H \cdot \gamma=58 \times 8=464 \mathrm{kPa}$

The leachate drainage system of Ya Hu Landfill Site in Shenzhen is mainly composed of HDPE pipelines. Pipelines of four different diameters were arranged under the landfill, Table 1 shows the specific parameters of the four pipelines:

Table 1 Pipe type and parameters

\begin{tabular}{ccccc}
\hline Type & $\begin{array}{c}\text { Nominal outside diameter } \\
\mathrm{D}(\mathrm{mm})\end{array}$ & $\begin{array}{c}\text { Wall thickness } \\
\mathrm{t}(\mathrm{mm})\end{array}$ & $\begin{array}{c}\text { Elastic modulus } \\
\mathrm{E}(\mathrm{MPa})\end{array}$ & $\begin{array}{c}\text { Tensile strength } \\
\mathrm{f}_{\mathrm{t}}(\mathrm{MPa})\end{array}$ \\
\hline DN300 & 300 & 20 & 194 & 21 \\
DN400 & 400 & 25 & 194 & 21 \\
DN500 & 500 & 30 & 194 & 21 \\
DN600 & 600 & 35 & 194 & 21 \\
\hline
\end{tabular}

The elastic modulus and tensile strength were chosen based on preference [5]. To determine the influence of the existing landfill stress and deformations that will be caused in the HDPE pipelines, it was necessary to assess the capability of the pipelines. Pipelines of type DN300 were chosen as example to assess the capability of the four pipelines.

\section{Calculation procedure}

Deformation checking of pipe ring cross section:

HDPE pipe was considered as a flexible pipe, which implied that under excessive load, only burst failure caused by deformation or instability will occur in the pipelines. At the same time, the deformation of the pipeline cannot exceed the allowable value. A number of documents and specifications suggest that the vertical pipe diameter deformation rate shall not exceed $5 \%$.

The vertical pipe diameter deformation is usually calculated using the formula proposed by Spangler-Iowa[6], and the formula is as follows:

$$
\Delta Y=\frac{D_{L} K W_{c} r^{3}}{E I+0.06 E^{\prime} r^{3}}
$$

Where: $\Delta Y$ is the vertical pipe diameter deformation; $K$ is a constant for pipe bottom cushion, which depends on the cushion angle, because the blind ditch is piled up by gravel ,if the cushion angle is not large, generally $K=0.1 ; D_{L}$ is deformation variation coefficient, when the vertical total load on the pipeline interface is regarded as the load $D_{L}=1 ; r$ is the pipe radius,$r=(D-t) / 2 ; W_{c}$ is the 
vertical load of per unit length, $W_{c}=\frac{H \gamma D}{1-n d}, n$ is the number of perforation of each row per unit length; $E$ is pipe-elastic modulus; $I$ is inertia moment, $I=t^{3} / 12 ; E^{`}$ is resilient modulus, $E$ ' $=2 E_{S}, E^{`}=66866 \mathrm{kPa}$.

All parameters were brought into equation (1), finally $\Delta Y$ was computed, $\Delta Y=0.00389$. Converting it into deformation percentage :

$\varepsilon=\frac{\Delta Y}{2 r} \times 100 \%=1.39 \%<5 \%$

Checking for pipeline deflection:

Pipe deflection is mainly caused by the lack of pipe stiffness. A flexible pipe can be bent due to the internal hollow and high external landfill soil pressure, so the control of deflection may play a key role in the design of the pipeline. Meyerhof and Baike [7] proposed using the following formula to calculate the critical deflection pressure of embedded pipelines:

$$
P_{c r}=2\left[\frac{E^{\prime} \cdot E I}{\left(1-v^{2}\right) r^{3}}\right]^{\frac{1}{2}}
$$

Where: $P_{c r}$ is the critical deflection pressure; $E^{`}$ is resilient modulus, $E{ }^{`}=66866 \mathrm{kPa} ; v$ is the Poisson ratio of pipe; $E$ is pipe-elastic modulus ; $I$ is inertia moment.

All parameters were brought into equation (2), finally $P_{c r}$ was computed, $P_{c r}=3976 \mathrm{kN} / \mathrm{m}^{2}$.

The maximum stress in the pipe was:

$$
P_{t p}=\frac{W}{D}=501 \mathrm{kN} / \mathrm{m}^{2}
$$

Where: $W$ is maximum upper load; $D$ is average diameter of pipe.

Generally, 2.0 is regarded as the safety factor used to design flexible pipes. That is to say that the safety factor shall be no less than 2 .

The safety factor in this case is:

$$
F_{s}=\frac{P_{c r}}{P_{t p}}=\frac{3976}{501}=7.94>2
$$

Checking for loop tension stress of pipe wall:

The loop tensile stress should be less than the design value of the tensile strength of the pipe, that is:

$\gamma_{0} \sigma \leq f_{t}$

Where: $\sigma$ is the loop tension stress of pipe wall; $\gamma_{0}$ is importance coefficient, for sewage pipe it equals 1 , for rainwater pipes it equals 0.9 , for rainwater and sewage pipe it equals 1 , here it equals $1 ; f_{t}$ is the design value of tensile strength.

The loop tensile stress was calculated by the following formula:

$$
\sigma=\frac{1.75 D_{f} E y_{0} K \gamma_{G} W_{c}}{4 r^{2}\left(E I / r^{2}+0.061 E^{\prime}\right)}
$$

Where: $D_{f}$ is the shape factor associated with the ring stiffness of the pipe and the packing density, here it equals 4.0; $y_{0}$ is the distance between pipe center and pipe wall; $\gamma_{G}$ is the practical safety factor for permanent load, $\gamma_{G}=1.27$.

All parameters were brought into the equation (3) and equation (4), finally $\sigma$ was computed, $\sigma=9458 \mathrm{kN} / \mathrm{m}=9.458 \mathrm{Mpa}<21 \mathrm{Mpa}$

After running checks on pipeline DN300 type, results show that this type of pipeline meets the 
design requirements.

\section{Result and Conclusion}

Table 2 - Table 4 show the calculation results of all the four different kinds of pipelines, the "conclusion" in the table means whether the results meet the design requirements.

Table 2 Deformation checking of pipe ring cross section

\begin{tabular}{ccccccccc}
\hline Type & $n$ & $I$ & $\begin{array}{c}W_{c} \\
(\mathrm{kN} / \mathrm{m})\end{array}$ & $\begin{array}{c}E^{\prime} \\
(\mathrm{kPa})\end{array}$ & $\begin{array}{c}\Delta Y \\
(\mathrm{~m})\end{array}$ & $\begin{array}{c}\text { Deformati } \\
\text { on ratio }\end{array}$ & $\begin{array}{c}\text { Allowable } \\
\text { deformation }\end{array}$ & Conclusion \\
\hline DN300 & 5 & $6.67 \mathrm{E}-07$ & 150.48 & 66866 & 0.0040 & $1.43 \%$ & $5.00 \%$ & Yes \\
DN400 & 5 & $1.30 \mathrm{E}-06$ & 200.64 & 66866 & 0.0054 & $1.43 \%$ & $5.00 \%$ & Yes \\
DN500 & 5 & $2.25 \mathrm{E}-06$ & 250.81 & 66866 & 0.0067 & $1.43 \%$ & $5.00 \%$ & Yes \\
DN600 & 5 & $3.57 \mathrm{E}-06$ & 300.97 & 66866 & 0.0081 & $1.43 \%$ & $5.00 \%$ & Yes \\
\hline
\end{tabular}

Table 3 Checking of pipeline deflection

\begin{tabular}{ccccccccc}
\hline Type & $\begin{array}{c}\mathrm{D} \\
(\mathrm{m})\end{array}$ & $\begin{array}{c}\mathrm{E} \\
(\mathrm{kPa})\end{array}$ & $\begin{array}{c}E^{`} \\
(\mathrm{kPa})\end{array}$ & $v$ & $\begin{array}{c}\mathrm{P}_{\mathrm{tp}} \\
\left(\mathrm{kN} / \mathrm{m}^{2}\right)\end{array}$ & $\begin{array}{c}\mathrm{P}_{\mathrm{cr}} \\
\left(\mathrm{kN} / \mathrm{m}^{2}\right)\end{array}$ & $\mathrm{F}_{\mathrm{S}}$ & Conclusion \\
\hline DN300 & 0.14 & 194000 & 66866 & 0.45 & 501.55 & 3975.85 & 7.92 & Yes \\
DN400 & 0.18 & 194000 & 66866 & 0.45 & 501.55 & 3584.97 & 7.14 & Yes \\
DN500 & 0.23 & 194000 & 66866 & 0.45 & 501.55 & 3358.59 & 6.69 & Yes \\
DN600 & 0.28 & 194000 & 66866 & 0.45 & 501.55 & 3211.08 & 6.40 & Yes \\
\hline
\end{tabular}

Table 4 Checking of loop tension stress of pipe wall

\begin{tabular}{ccccccccc}
\hline Type & $\begin{array}{c}\mathrm{D} \\
(\mathrm{m})\end{array}$ & $\begin{array}{c}W_{c} \\
(\mathrm{KN} / \mathrm{m})\end{array}$ & $\begin{array}{c}E^{`} \\
(\mathrm{kpa})\end{array}$ & $\begin{array}{c}\mathrm{E} \\
(\mathrm{kpa})\end{array}$ & $\begin{array}{c}\mathrm{W}_{\mathrm{c}} \\
\left(\mathrm{KN} / \mathrm{m}^{2}\right)\end{array}$ & $\begin{array}{c}\sigma \\
(\mathrm{Kpa})\end{array}$ & $\begin{array}{c}\mathrm{F} \\
(\mathrm{Kpa})\end{array}$ & Conclusion \\
\hline DN300 & 0.14 & 150.48 & 66866 & 194000 & 150.49 & 9458.89 & 21000 & Yes \\
DN400 & 0.18 & 200.64 & 66866 & 194000 & 200.65 & 16746.89 & 21000 & Yes \\
DN500 & 0.23 & 250.81 & 66866 & 194000 & 250.81 & 26038.43 & 21000 & No \\
DN600 & 0.28 & 300.97 & 66866 & 194000 & 300.97 & 37281.28 & 21000 & No \\
\hline
\end{tabular}

Table 2 to 4 show that with the exception of loop tension stress check of pipe wall, all the four kinds of pipelines met the code requirements. In checking of loop tension stress of pipe wall, for the type DN500 and DN600, loop tension stress of the pipeline was greater than the yield stress of the pipeline, indicating that the pipelines may be damaged and requires special attention. Better still the two types of pipelines should be replaced under the landfill.

From the results we also know that due to the differences of diameter and wall thickness different HDPE pipelines have different responses to the upper load.

\section{Acknowledgement}

The authors appreciate the supports provided by the National Natural Science Foundation of China (No.51578214, 41530637) and Fundamental Research Funds for the Central Universities (No. 2015B17714) 


\section{References}

[1] Wang Gang, Bai Yan, Treatment Mode of Domestic Waste in Medium and Small Sized Cities[J], Environmental Sanitation Engineering,2008 16 (6) :54-57.

[2] ZHANG Zhen-ying , CHEN Yun-min, Settlement model of municipal solid waste landfill[J], Journal of Zhejiang University( Engineering Science),2004,38 (9) :1162-1165.

[3] Yang Yiqing, Application of HDPE Geomembrane to Leachate Control of Waste Landfill Site Basement[J],Environmental Sanitation Engineering,2001 9(3) :116-119.

[4] ZHOU Min, DU Yan-jun, WANG Fei, YOU Quan, DONG Dong-dong, Physical modeling of mechanical responses of HDPE pipes and subsurface settlement caused by land subsidence[J], Chinese Journal of Geotechnical Engineering,2016 38(2) :253-262.

[5] CAO Ke,BAI Shu-lin,CHEN Jian-kang,YU Zhong-zhen, Tensile properties of GB /HDPE composites and their influence factors[J],Journal of Aeronautical Materials,1999 19(4) 32-37.

[6] MARSTON A. The theory of external loads on closed conduits in the light of the latest experiments[J]. Iwoa Engineering Experiment Station, 1930, 96( 9): 138-170.

[7] GG Meyerhof,LD Baikie, Strength of Steel Culvert Sheets Bearing Against Compacted Sand Backfill[J], Highway Research Record, 1963 